Research Article

\title{
State Judgement Model of the Coal and Rock Medium and Its Engineering Application
}

\author{
Chuanqi Zhu $\mathbb{D}^{1}{ }^{1}$ Lei Wang, ${ }^{1}$ and Xiangang Han ${ }^{2}$ \\ ${ }^{1}$ State Key Laboratory of Mining Response and Disaster Prevention and Control in Deep Coal Mines, \\ Anhui University of Science and Technology, Huainan 232001, China \\ ${ }^{2}$ College of Civil Engineering, Hebei University of Engineering, Handan 056038, China \\ Correspondence should be addressed to Chuanqi Zhu; cqzhu@aust.edu.cn
}

Received 21 January 2020; Revised 18 May 2020; Accepted 3 June 2020; Published 22 June 2020

Academic Editor: Emanuele Brunesi

Copyright (C) 2020 Chuanqi Zhu et al. This is an open access article distributed under the Creative Commons Attribution License, which permits unrestricted use, distribution, and reproduction in any medium, provided the original work is properly cited.

In the loading and failure process of the coal and rock medium, with the increasing of the damaging and failure extent, the medium state gradually changed from the continuous, the quasicontinuous, and the discontinuous to the loose successively. To evaluate the damaging failure extent of the coal and rock mass and distinguish the state of the coal and rock mass medium, first, the medium state index was defined based on the acoustic wave propagation model. Then, based on the coal mass in the working face 8512 in the Chenjiagou Coal Mine in China, the acoustic character and the mechanical character experiments were conducted. Through experiments, the variation law of the ultrasonic wave velocity and the medium state index of the coal mass with the strain under the compressive state were acquired; with the increasing of the strain, the medium state indexes successively experienced the variation process including stabilising around 0 , slow increasing, dramatic increasing, and stabilising around 1 . Then, based on the variation law of the medium state index, the coal and rock mass medium state judgement model was constructed. This model was applied to judge the coal mass medium state. After it, the mudstones in the roof of the same working face were regarded as the research object, the mudstone medium state was divided into 4 types according to the medium state judgement model, namely, continuous, quasicontinuous, discontinuous, and bulk solid, and the mudstone failure state was basically consistent with the continuous, quasicontinuous, discontinuous, and bulk solid state. The adaptability and rationality of the judgement model was verified. Finally, engineering application of the judgement model was conducted. The distribution law of the top coal with different medium state was acquired. In the top coal that was $186 \mathrm{~m}$ away from the working face, it belonged to the continuous medium state. As for the top coal that was $6 \mathrm{~m}$ to $186 \mathrm{~m}$ far away from the working face, it was under the quasicontinuous medium state. For the top coal that was $3 \mathrm{~m}$ to $6 \mathrm{~m}$ far away from the working face, it was under the discontinuous medium state. For the top coal that was less than $3 \mathrm{~m}$ far away from the working face and behind the working face, it belonged to the bulk solid medium state. The state judgement model can successfully distinguish the medium state of the coal seam and mudstones in the roof in the working face 8512. This provided a new approach to evaluate the damaging failure extent of the coal and rock medium in the Chenjiagou Coal Mine.

\section{Introduction}

The development and generation of the underground engineering disasters in rock masses has a direct relationship with the damaging, failure, and degradation of the rock masses. The rational and effective description of the damaging failure process of rock masses and evaluation of the damaging failure extent of rock masses have a significant practical role in grasping the mechanical state of rock masses and predicting the underground engineering disaster. Recently, a number of scholars conducted research on the damaging failure process and state. The indexes that can describe the damaging failure extent of rock masses were also proposed [1-5].

Aiming at the precast crack specimen, Afolagboye et al. [6], Cheng et al. [7], and $\mathrm{Xu}$ and $\mathrm{Li}$ [8] conducted laboratory experiments and discussed the full process including the crack developing, cutting through, and the specimen 
instability and failure. Aliha et al. [9] regarded the rigid polyurethane foam plastics with different types of cracks (types I, II, and III) as the research object. They conducted experiments to study the generation and development law of cracks. Gao et al. [10] proposed a new rupture criterion in which the rock masses with cracks were included. Based on this rupture criterion, the failure process of rock mass slope which had the initial cracks was analysed. Aiming at the nonhomogeneous material, Liu et al. [11] conducted numerical simulation with the R-T2D coding to show the progressive damaging process of rock masses, based on the finite element method and the RFPA model. Based on the continuum damage-embedded discontinuity model, Saksala [12] acquired the rupture process of the rock masses under the dynamic loading effect. Aiming at the composite beam of the rock and concrete, Dong et al. [13] simulated the rupture process of the composite beam through introducing the initial rupture criterion. Sarfarazi et al. [14] used the twodimensional particle flow code to study the influence of joint overlap on the full damaging character of the rock bridge beam in the shear experiments. Aiming at the rock masses similar to the tower, He et al. [15] studied three movement stages including initiating, accelerating, and decelerating in the instability process of rock masses. Xie et al. [16] applied the fractal theory and incorporated the fractal dimensions, fractal effect, and fractal geometry. They systematically and comprehensively studied the micro, tiny, and macro mechanical behaviour in the damaging process of the loaded rock blocks, such as the damaging evolution extent, rupture characters, and the rupture face state. Tang et al. $[17,18]$ used the developed numerical simulation software (RFPA) to vividly and visually show the full instability and failure process of rock blocks. Wang et al. [19] used FLAC3D software to study the energy change associated with longwall mining.

Mosleh et al. [20] introduced an abrasive wear index for rocks and soils. The abrasive wear theory was used to determine parameters. Furthermore, the quantitative evaluation method of this index was discussed. Chen et al. [21] introduced to generalised RQD. Based on the modified block index (MBI), the optimum threshold of the generalised RQD was determined. The differences between the traditional and generalised RQDs results were discussed. To evaluate the hydration damaging extent of the muddy shale, Liu et al. [22] proposed the hydration damaging index. Additionally, the hydration constitutive law was constructed. Shan et al. [23] developed an $\mathrm{AE}$ quantification method of fatigue damaging in concrete. Particularly, the AE and a fibre bundle-based statistical damage model (fibre-bundled irreversible chain model) were combined. The credibility of this model was validated with experimental results. Based on the acoustic emission parameters, Zhang et al. [24] defined the damaging variables. Furthermore, the rock mass microbody assumption and the Weibull distribution function were applied to improve the damaging variables. The damaging constitutive law based on the three-point bending for the limestones was constructed. Through the uniaxial compressive strength test, Sygala and Bukowska [25] observed the variation law between the residual strength of sandstones and strain after elevated temperature. Then, the critical parameter evaluation and the result analysis method for the rocks after elevated temperature were proposed. Shirole et al. [26] used the linear ultrasound detecting technology to dynamically analyse the damaging effect on the strain evolution process. Combined with the LUT program, the noncontact optical full-field displacement observing method that was related to the two-dimensional digital image was proposed.

According to the rock mass deformation, failure mechanism, and in situ stress distribution characters, Sun [27] classified the rock masses as continuous medium, cracked medium, slab breaking medium, and block breaking medium. Furthermore, they studied the mechanical character of rock masses with different mediums. Wang et al. [28] classified the moving and damaging of the overlying rock strata above the coal working face into three medium states: the continuous medium before rupture, the quasicontinuous medium before the complete rupture, and the discontinuous medium before the complete rupture. Zhang et al. [29] defined the index of the rock yielding proximity and the index of the damaging extent. Then, they combined those two indexes together, forming a single damaging proximity index. Based on this, they properly evaluated the damaging and failing extent of rock blocks. Li et al. [30] considered the gradual dynamic failure characters of rock blocks, proposing the cracking extent concept. They developed the evaluation method for the damaging and failure status of rock blocks. Wang et al. [31] regarded the transferring of the mechanical state of the top coal in the fully mechanised caving mining as the object. Based on the acoustic and mechanical character of the coal mass under the compressive state, they classified the top coal medium state into five states: (I) the original failure, (II) regeneration of the failure in the local area, (III) the penetrating failure, (IV) the cracking failure, and $(\mathrm{V})$ the moving failure.

Before the excavation of the underground engineering, the rock mass can be regarded as the continuous medium. After the excavation is completed, the rock masses around the excavation area generate deformation, failure, and even displacement. In this area, the rock masses are bulk solids. In the initial loading period, the particles are distributed continuously, belonging to the continuous medium state. After that, the number of fractures and the volume gradually increase. Among the particles, movement and slippage occurred. This is the quasicontinuous medium state. Following it, the internal fractures in the rock masses are converged and connected. This is the discontinuous medium state. Finally, in the rock masses, a macro connected plane occurs or even multiple macro connected planes may occur. The rock blocks slip along the connected plane, belonging to the bulk solid medium state [32]. During the instability and failure process of rock masses, with the increasing of the damaging and failure extent, the medium state shows the core character that gradually changes from continuous, quasicontinuous, discontinuous, and bulk solid. The transferring of the rock mass medium state is regarded as the entry point. The medium state evaluation index was studied. Furthermore, the medium state evaluation system was constructed, which has significant engineering practice value and significance. 
Under the continuous external loading, the generation of the new fractures in the internal area of rock masses and the development of the original fractures directly lead to the changing of the rock mass medium state. The acoustic character can effectively reflect the developing and extending situation of the internal structure of rock masses. The acoustic wave detecting technology has already been widely applied in studying the damaging evolution law and the damaging extent evaluation in rock masses [33-35]. Based on this, aiming at the coal and rock masses in the working face 8512 in the Chenjiagou Coal Mine in China, this study used the acoustic character to reflect the generating and developing state of the internal fractures in coal and rock masses. According to the acoustic wave character parameters, a damaging state evaluation index was defined. The medium state judgement model was constructed. Furthermore, the applicability and the rationality of the judgement model were verified.

\section{Definition of the Medium State Index}

Assuming that the rock masses are homogeneous before being subjected to loading, and there are completely no fractures, the loading of rock masses makes the fractures generate and develop in the internal area. The acoustic wave propagation model as shown in Figure 1 was constructed. When the ultrasonic wave propagates in the internal area of rock masses that completely do not have fractures, the sonic time $t_{0}$ is

$$
t_{0}=\frac{L}{v_{0}},
$$

where $L$ is the specimen width, $m ; v_{0}$ is the propagation velocity of the acoustic wave in the internal area of rock masses that completely do not have fractures, $\mathrm{km} \cdot \mathrm{s}^{-1}$. With the continuous loading, in the internal area of rock masses, fractures gradually generate and develop. When the ultrasound wave propagates in the internal area of rock masses that have fractures, the acoustic wave that is launched by the emission probe needs to go through not only the rock blocks, but also the fractures. Then, it can propagate to the receiving probe. If the number of fractures along the propagation pathway of the acoustic wave is $N$ and the sonic time is $T$, the following equation can be acquired:

$$
T=t_{0}+\sum_{i=1}^{i=N} t_{i}
$$

where $t_{i}$ is the time that the acoustic wave goes through the fracture $i$. Furthermore, it is equal to the sum between the propagation time of the acoustic wave in the internal fractures in rock masses and the wasting time that is due to the reflection and the transmission in the propagation on the medium interface.

Combining with equation (1), it is defined that the rock mass medium state index $K$ is the ratio between the time that is needed for the acoustic wave to go through the rock mass in a certain damaging failure state and the time that is needed for the acoustic wave to go through the rock mass that is completely damaged and failed. Then, the following equation can be acquired:

$$
K=\frac{\sum_{i=1}^{i=N} t_{i}}{\sum_{i=1}^{i=M} t_{i}},
$$

where $N$ and $M$ are the number of fractures along the acoustic wave propagation pathway when the rock masses are in a certain damaging failure state and after the complete damaging failure. Combining with equations (2) and (3), the following equation can be acquired:

$$
K=\frac{T-t_{0}}{T_{m}-t_{0}},
$$

where $T$ and $T_{m}$ are the sonic time when the rock masses are under a certain damaging failure state and after the complete damaging failure. Using the sonic velocity to indicate the medium state index leads to

$$
K=\frac{\left(v_{0}-v_{\rho}\right) v_{m}}{v_{\rho}\left(v_{0}-v_{m}\right)},
$$

where $v_{\rho}$ and $v_{m}$ are the sound velocity of the rock masses under a certain failure state and after the complete instability failure. With the $K$ value decreasing, the rock masses are likely to be in the intact state, while with $K$ increasing, the damaging failure extent of rock masses is higher. $K$ is an acoustic index that comprehensively reflects the transition degree of the medium state based on ultrasonic propagation information.

\section{Observation of the Medium State Indexes}

Aiming at the coal masses in the working face 8512 in the Chenjiagou Coal Mine in China, the acoustic character and the mechanical character experiments of the loaded rocks were designed. The ultrasonic time of the coal masses under a certain time was observed. Based on the observed sonic time data, equation (4) was used to calculate the coal mass medium state index $(K)$ under a certain time. According to the sonic time variation law in the coal mass instability failure process, the variation law of the medium state index can be acquired.

3.1. Sample Preparation. The sample coring depth was around $-560 \mathrm{~m}$. To conveniently stabilise the ultrasonic wave probe along the two sides of the sample, the mechanical cutting and grinding was conducted. Then, the original samples were cut to cuboids with length of $50 \mathrm{~mm}$, width of $50 \mathrm{~mm}$, and height of $100 \mathrm{~mm}$. To guarantee that the top surface and bottom surface of samples are smooth and flat and the parallelism is smaller than $\pm 0.02 \mathrm{~mm}$, the samples that have less original defects were used for experiments. Prepared samples are shown in Figure 2.

3.2. Experiment Equipment and System. The experimental system is shown in Figure 3. It includes three sections, namely, the stress loading system, the stress and strain collecting system, and the acoustic wave collecting system. 


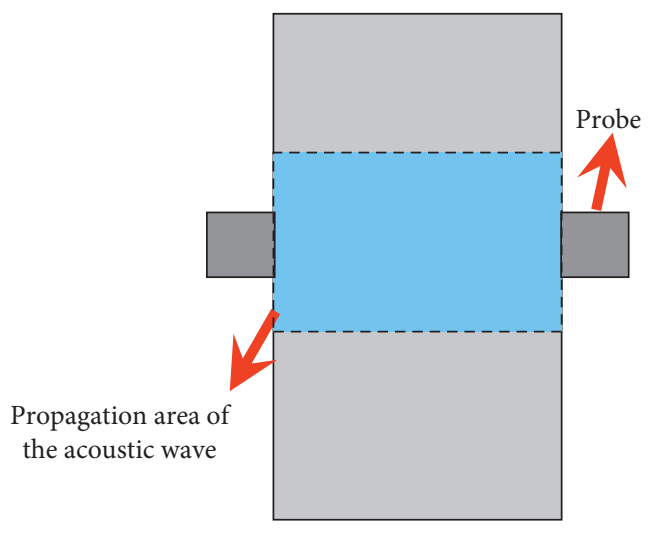

(a)

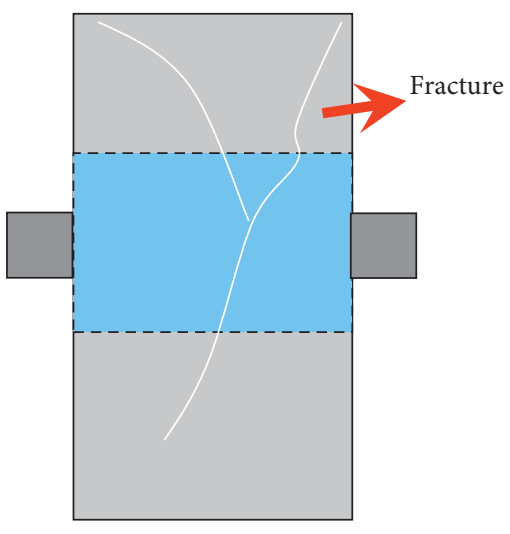

(b)

FIgURe 1: Acoustic wave propagation model. (a) No fracture and (b) fractures included.

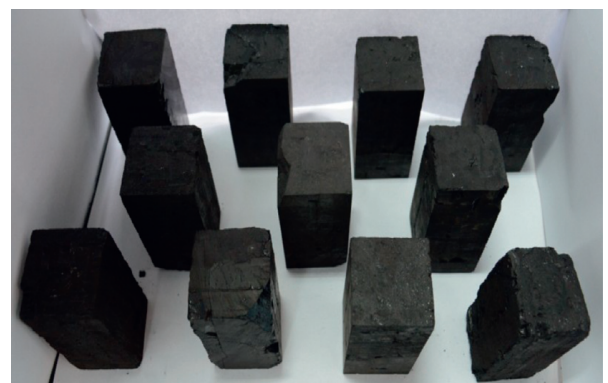

Figure 2: Prepared samples in the laboratory.

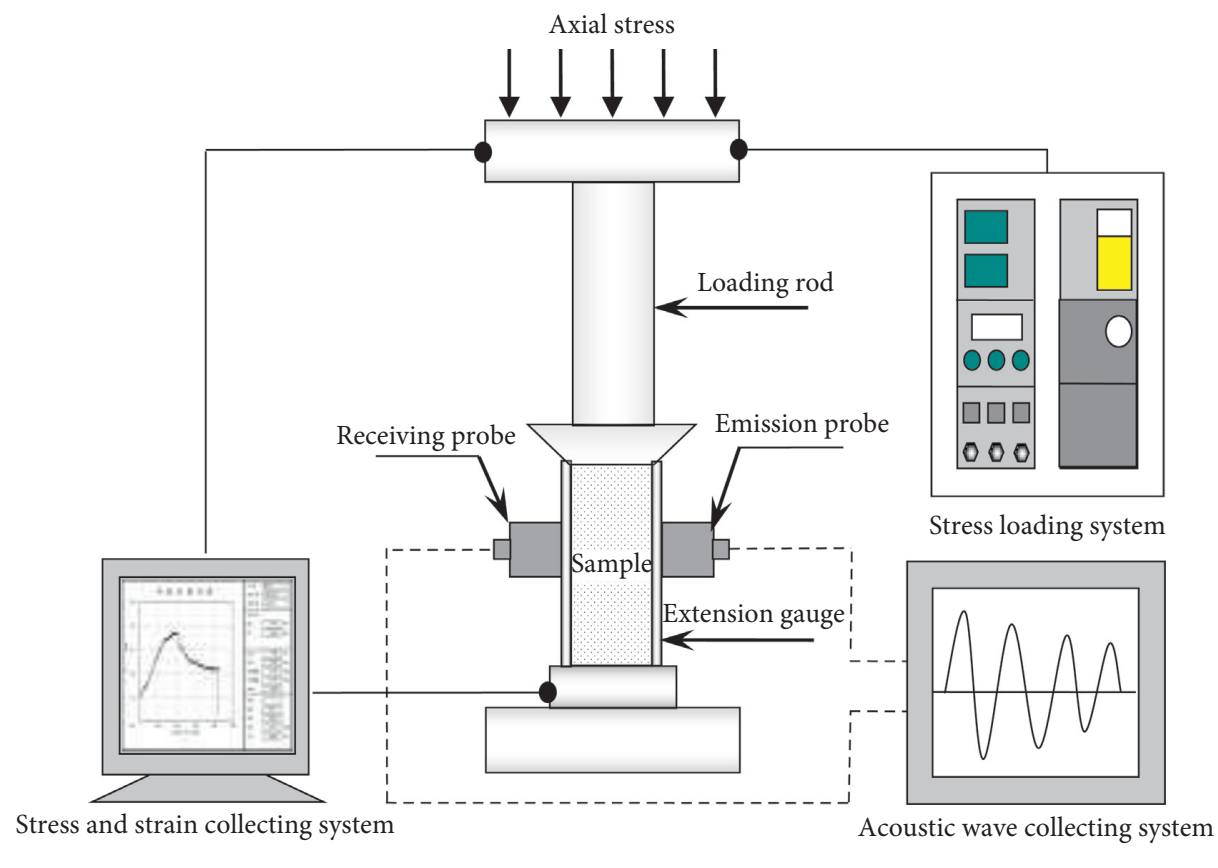

FIgURE 3: The test system of coal-rock acoustic features under loading.

Among them, the stress loading system and the stress and strain collecting system are supplied by the electrohydraulic servo rock triaxial test rig (TAW-2000). The acoustic wave collecting system includes the nonmetal ultrasonic detecting analysis metre (NM-3C), the acoustic wave emission probe, and the acoustic wave receiving probe. The acoustic character experimental system for the loaded rocks combines the mechanical character observation instrument for rocks and 
the acoustic wave character observation instrument. Then, it can monitor the acoustic characters and mechanical characters in the coal mass and rock mass failure process dynamically.

3.3. Experiment Steps. First, a sample was taken out. On the two lateral surfaces of the sample, Vaseline was painted uniformly. Then, the ultrasonic wave emission probe and the receiving probe were fixed successively.

Then, the emission probe and the receiving probe were connected with the ultrasonic wave detecting analysis instrument. The sampling period was set as $0.2 \mathrm{us}$. The analysis instrument was debugged until the signal was stable.

Following it, around the sample, the extension gauge was installed. The sample and the acoustic wave probe were put on the bench of the testing machine.

After that, the testing machine was initiated. The uniaxial compressive strength (UCS) test was conducted. Specifically, the displacement control was used and the loading rate was $0.03 \mathrm{~mm} / \mathrm{min}$. This was conducted until the sample failed. In the whole experimental process, the sample strain and the sonic time of the ultrasonic wave were recorded dynamically.

Last, the other samples were taken out successively. The procedures from the first to the fourth were repeated.

\section{Medium State Judgement Model}

To use the acoustic character to fully reflect the generating and developing situation of the internal fractures in coal masses, four representative samples in which the fracture surface was perpendicular to the acoustic wave propagation direction were collected. According to the experimental results, Figure 4 shows the coal medium state index under the UCS condition-strain curve (under the bulk solid medium state, the coal block slips along the fracture surface. To acquire the complete stress-strain curve, the ratio between the axial displacement of the sample and the height under the bulk solid state was regarded as strain). The analysis shows that due to the difference of samples, the coal mass medium state indexes are not different. A certain discreteness is shown. However, overall, with the increasing of the strain, all the medium state indexes successively experienced the variation process including stabilising around 0 , slow increasing, dramatic increasing, and stabilising around 1 . The sample $1 \#$ was regarded as an example. Four variation stages of the sound velocity were the sections $A B, B C, C D$, and $D E$ in the figure. Section $A B$ indicates that when the coal mass strain increased from 0 to $4.4 \times 10^{-3}$, the variation of $K$ was quite small. In fact, it stabilised around 0 . Section BC shows that with the strain increasing, $K$ had the tendency to increase slowly. Particularly, it increased to 0.04332 when the strain was $6.0 \times 10^{-3}$. Section CD indicates that when the sample strain increased from $6.0 \times 10^{-3}$ to $12.74 \times 10^{-3}, K$ increased from 0.4332 to 1.02888 . When the strain increased by every $1 \times 10^{-3}, K$ would increase to 0.1462 . Section DE shows that with the strain increasing, $K$ always stabilised around 1 although there was fluctuation of $K$.
According to the variation rule of the medium state index, the coal and rock mass medium state judgement model was proposed. When the coal and rock mass medium state index $K$ is around 0 , which is in the stable stage, the coal and rock masses are under the continuous medium state. When $K$ is in the gradual increasing stage, it is under the quasicontinuous medium state. When $K$ is in the dramatic increasing stage, it is under the discontinuous medium state. When $K$ is around 1, which is in the stable stage, it is the bulk solid medium state, as shown in Table 1 .

The medium state judgement model was applied to judge the medium state of coal masses, as shown in Figure 4. In stage I, with stress increasing, the medium state index was always around 0 . And the coal mass was under the continuous medium state. In stage II, with stress further increasing, the medium state index increased gradually. And the coal masses were under the quasicontinuous medium state. In stage III, with further loading, the medium state increased rapidly within a short time period. And the coal masses were under the discontinuous medium state. In stage IV, the coal mass medium state index was around the maximum (around 1) in this stage. And it was likely to be stable. The coal mass was under the bulk solid medium state.

\section{Applicability and Rationality of the Medium State Judgement Model}

To verify the applicability of the medium state judgement model, the mudstones in the roof of the working face 8512 in the Chenjiagou Coal Mine was regarded as the research object. The experiment and the calculating method that were the same as shown in Section 3 were used to measure the variation law of the mudstone medium state index with the strain, as shown in Figure 5. The analysis shows that with strain increasing, the mudstone medium state index also showed the variation tendency from being stable, gradual increasing, dramatic increasing, and restabilising. According to the medium state judgement model, the mudstone medium state was divided into 4 types, namely, continuous, quasicontinuous, discontinuous, and bulk solid. They are corresponding to those 4 stages, namely I, II, III, and IV in Figure 5.

To verify the rationality of the medium state judgement model, the surface state in the mudstone failure process of $1 \#$ was recorded, as shown in Figure 6. Combined with Figure 5(a), the analysis shows that when $K=0$, the sample was under the intact state and it was the continuous medium, which is shown in Figure 6(a). When $K=0.02162, K$ was in the gradual increasing stage. The mudstones were under the quasicontinuous medium state. In the internal area of the sample, at the end of the micro fracture, stress concentration occurred. This promoted the initiation and development of fractures. Furthermore, massive micro fractures started to increase, as shown in Figure 6(b). When $K=0.03784, K=0.28108$, and $K=0.38919$, $K$ was under the dramatic increasing stage. The mudstone was under the discontinuous medium state. In the internal area of the mudstones, the micro fractures further developed, generating the micro fracture zone. The fractures gradually 


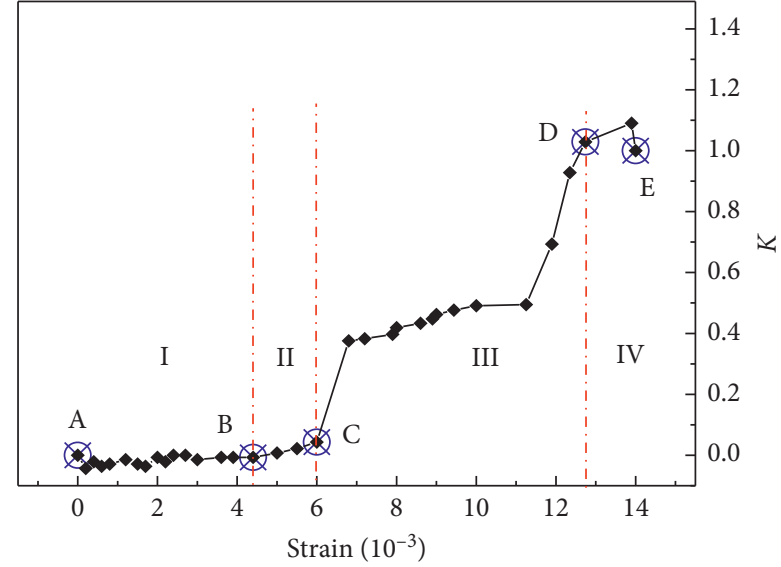

(a)

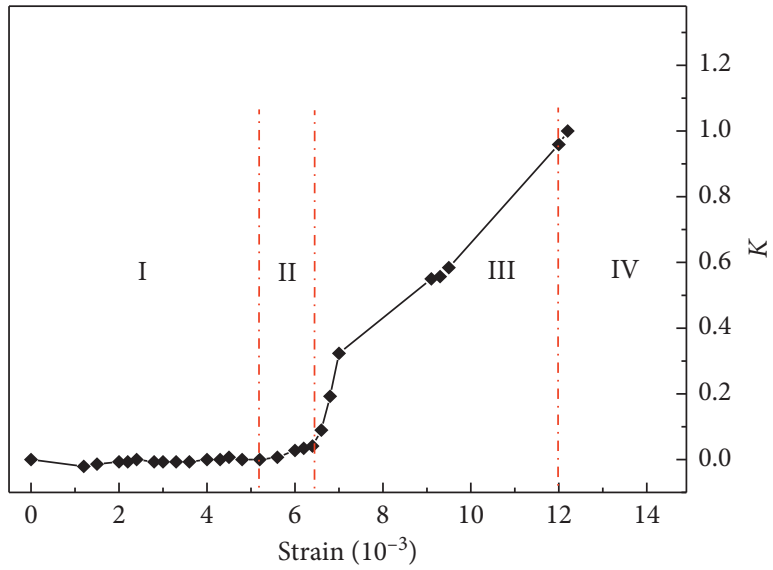

(c)

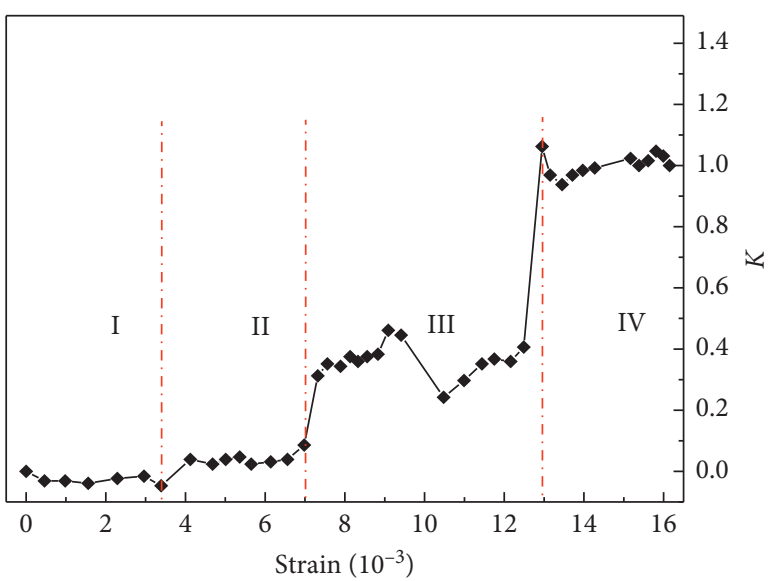

(b)

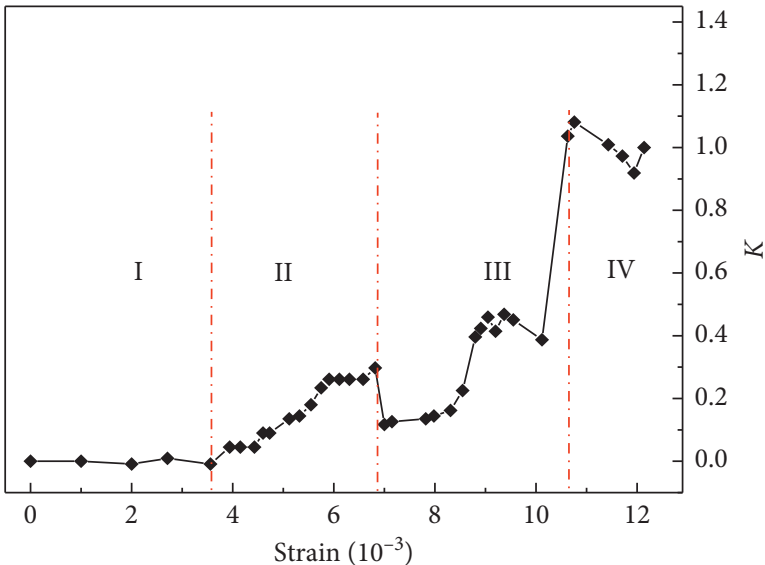

(d)

Figure 4: The coal mass medium state index-strain curve. (a) Coal sample 1\#. (b) Coal sample 2\#. (c) Coal sample 3\#. (d) Coal sample 4\#.

TABLE 1: Medium state judgement model.

\begin{tabular}{lcccc}
\hline Medium state & Continuous & Quasicontinuous & Discontinuous & Bulk solid \\
\hline$K$ & Around 0 & Increase gradually & Increase dramatically & Around 1 \\
\hline
\end{tabular}

mingled, joined, and connected. The sample surface state varied dramatically. The macroscopic fractures which are generally parallel with the axial stress direction generated. The damaging apparently increased, as shown in Figures $6(\mathrm{c})-6(\mathrm{e})$. When $K=1, K$ was around 1, being under the stable stage. The mudstones were under the bulk solid medium state. The internal fractures in the sample fully developed. And the number of fractures was maximal. Several macroscopic local fractures would connect and develop along a weak pathway and several weak pathways, forming a macroscopic connected plane. They may also form multiple macroscopic connected planes. The rock blocks would slip along the connected face. Full damaging failure occurred. The sample is shown in Figure 6(f). Overall, the sample failure state was basically consistent with the continuous, quasicontinuous, discontinuous, and bulk solid state. Therefore, applying the medium state judgement model to judge the mudstone medium state was rational.
Literature [36] and this article both used ultrasonic detection technology to study the evolution law of ultrasonic propagation information in the failure process of coal and rock under compression, and the damage degree of coal and rock is evaluated. Zhang et al. [36] divided the damage area of coal and rock into four types: no damage, weakened damage, moderate damage, and severe damage, and used the wave speed of different damaged areas to calculate the coal and rock damage variables. In this paper, based on the essential features of medium state transition, the evaluation index of medium state transition degree is defined according to the acoustic features of coal and rock, and the relation between the ultrasonic sound and the destruction degree is obtained. Quantitative characterization of the destruction degree of coal and rock is achieved, and a model for judging the state of coal and rock media is constructed based on the variation law of indicators with strain. The coal and rock at different failure stages are divided into four media states by 


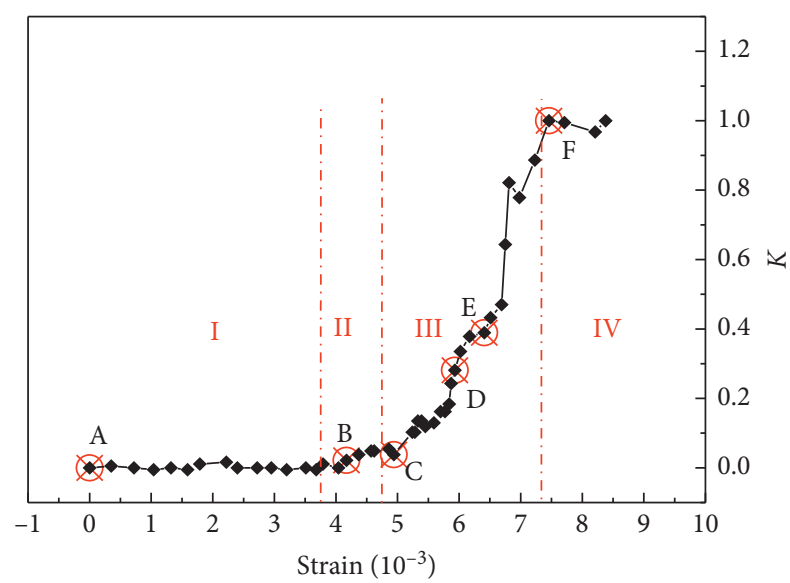

(a)

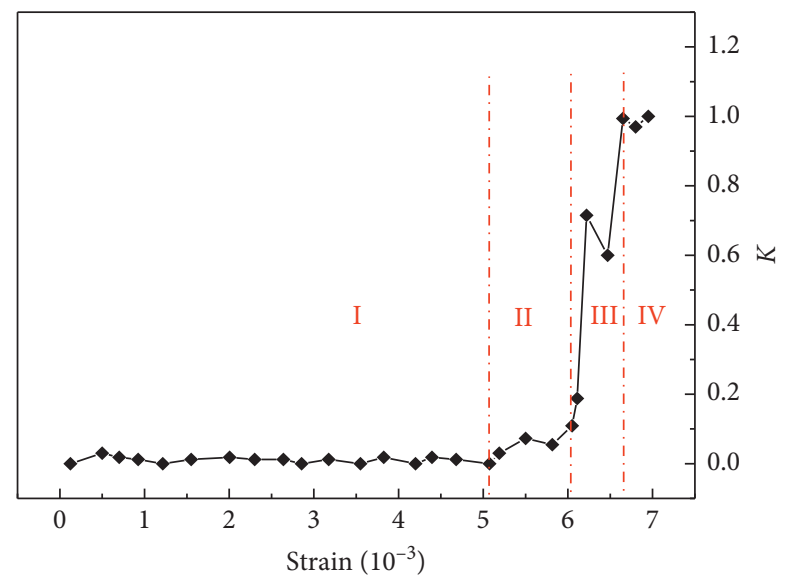

(c)

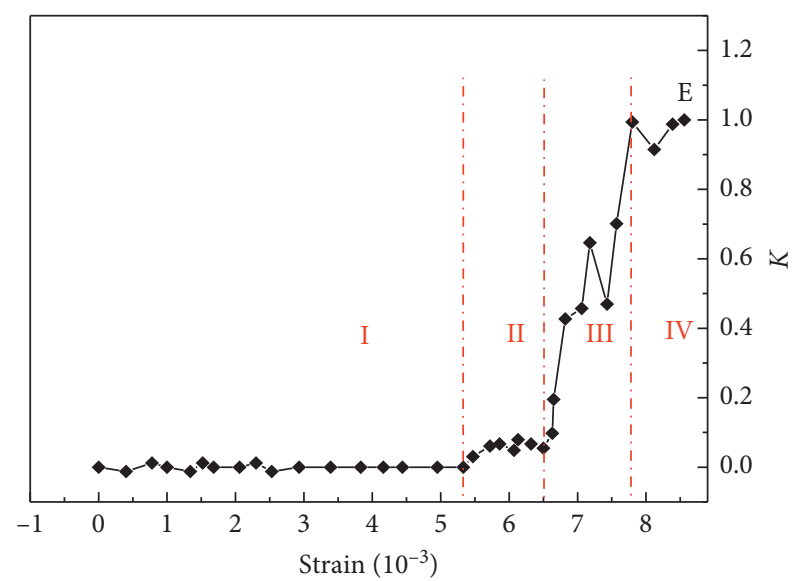

(b)

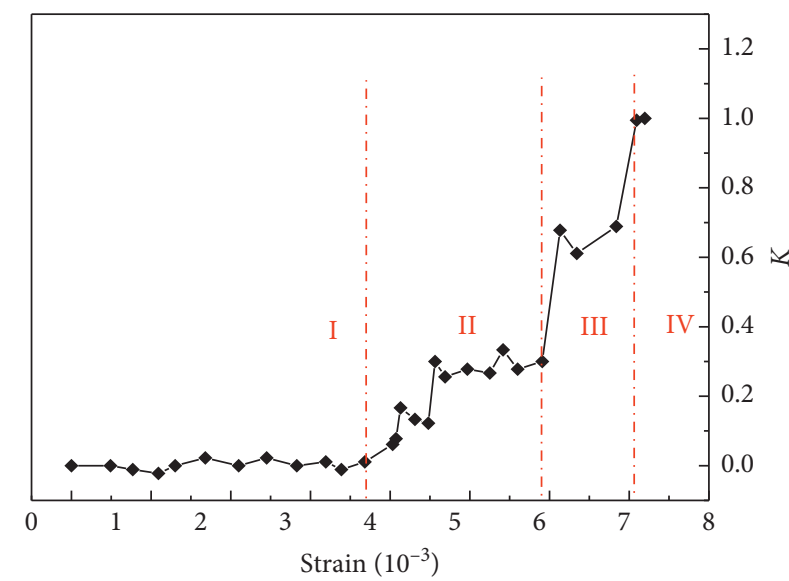

(d)

Figure 5: The variation rule of the medium state index with strain. (a) Rock sample 1\#. (b) Rock sample 2\#. (c) Rock sample 3\#. (d) Rock sample $4 \#$.

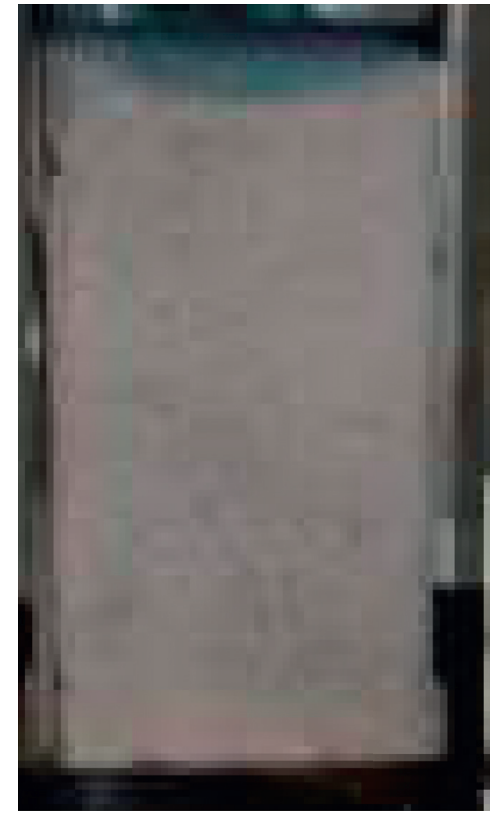

(a)

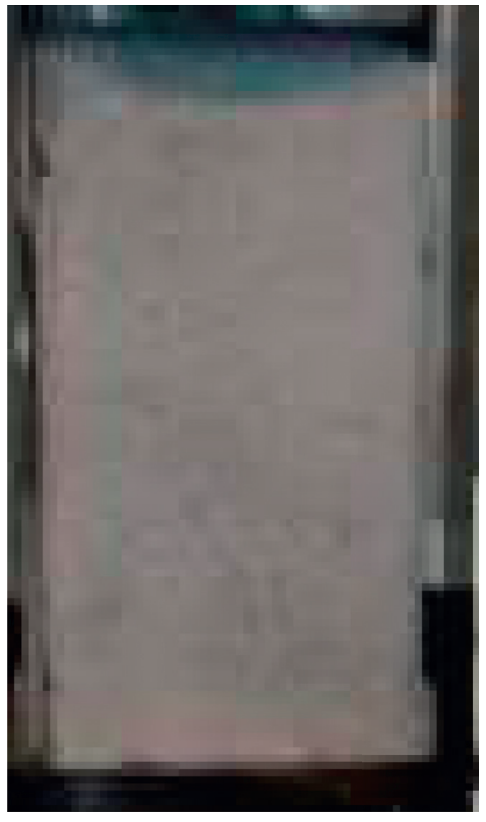

(b)

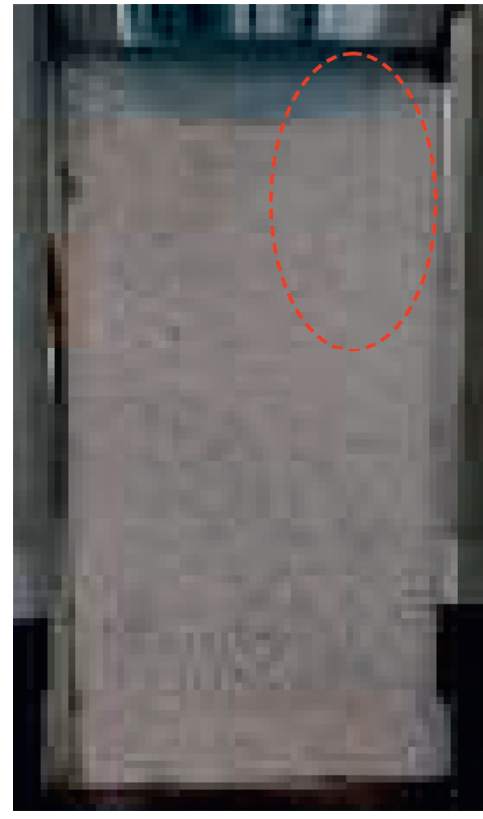

(c)

Figure 6: Continued. 


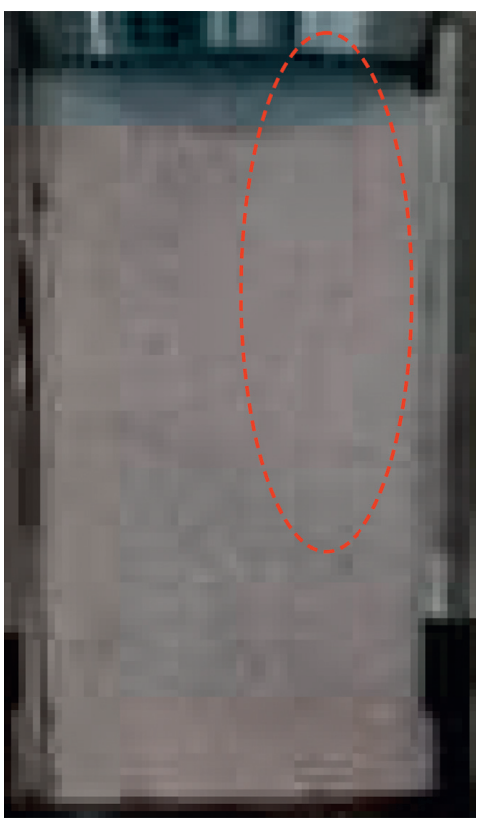

(d)

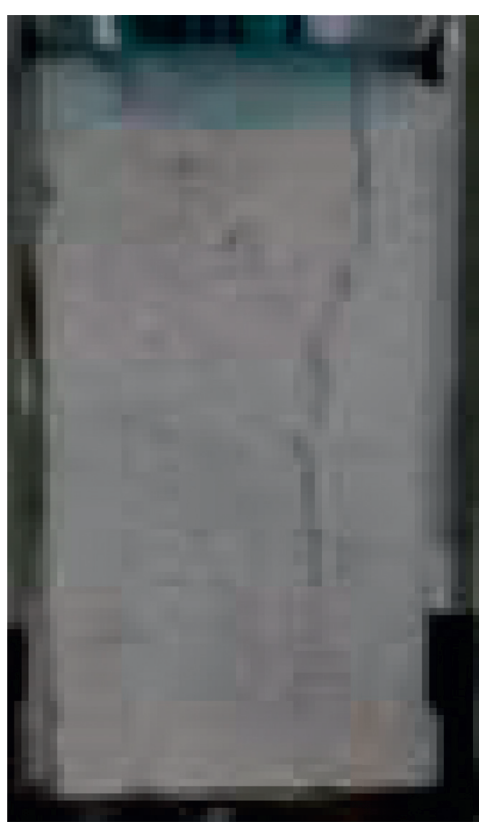

(e)

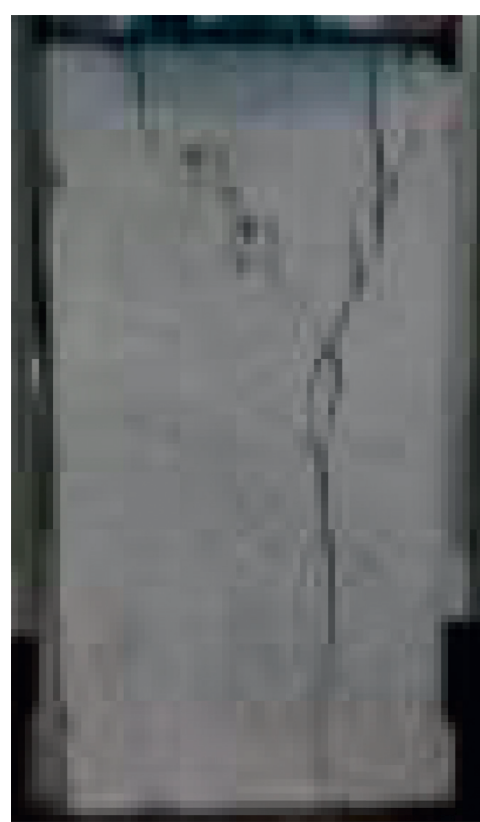

(f)

Figure 6: Failure process of sample $1 \#$. (a) $K=0$. (b) $K=0.02162$. (c) $K=0.03784$. (d) $K=0.28108$. (e) $K=0.38919$. (f) $K=1$.

using the judgement model: continuous state, quasicontinuous state, discontinuous state, and discrete state. The media state of coal and rock is reasonably determined. It provides a new idea for studying the whole failure process of coal and rock and innovating the evaluation method of the degree of destruction.

\section{Engineering Application}

The working face 8512 in the Chenjiagou Coal Mine had two sublayers. The thickness of the sublayer ranged from $8.5 \mathrm{~m}$ to $18.8 \mathrm{~m}$. The mean thickness was around $12 \mathrm{~m}$. The coal seam dip angle ranged from 3 to 10 degrees. The average coal seam dip angle was 6 degrees. The fully mechanised top coal caving mining method with longwall face along the strike direction was adopted. Also, the full roof collapsing method was used to manage the roof. To conduct the engineering application of the coal and rock mass medium state judgement model, using JY-80A rock ultrasonic testing analyzer, as shown in Figure 7, the ultrasonic wave velocity measuring experiment for the top coal in the working face 8512 was performed. The specific measuring scheme is shown below.

In the air-return roadway and the transport roadway that are in front of the working face for $200 \mathrm{~m}$, the observation station was arranged. In each observation station, the sound velocity observation hole was set. The diameter of the drilled borehole was $48 \mathrm{~mm}$ and the length of the drilled borehole was $20 \mathrm{~mm}$. The elevation angle of the drilled borehole was 20 degrees. The intersection angle between the drilled borehole and the strike direction of the roadway was 40 degrees. The vertical height of the probe that was installed in

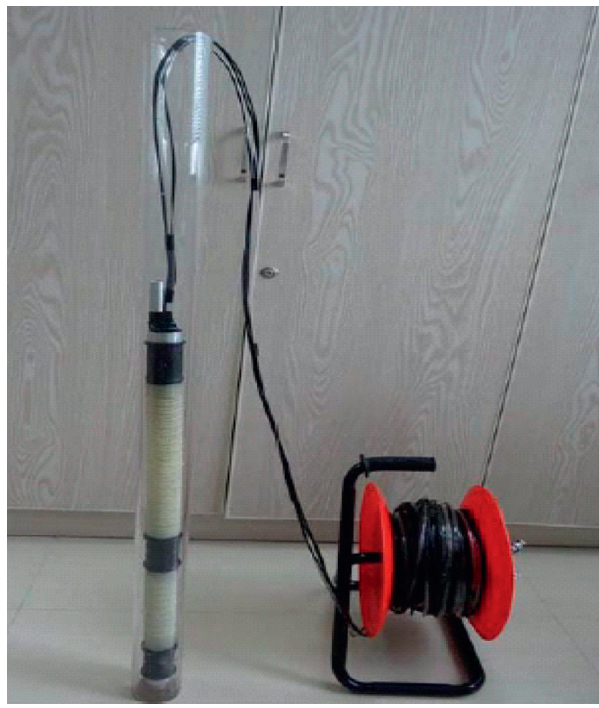

FIGURE 7: JY-80A rock ultrasonic testing analyzer.

the coal masses was $5.23 \mathrm{~m}$. The vertical height between it and the floor was $8.23 \mathrm{~m}$, as shown in Figure 8 .

According to the sound velocity data that was observed in the field, (5) was used to calculate the medium state index of the top coal $(K)$, when the distance to the working face $(l)$ was different. Figure 9 shows the variation tendency diagram of the top coal medium state index $(K)$ along the coal seam strike direction, when $l$ was different. The analysis shows that when $l$ was larger than $186 \mathrm{~m}, K=0$. When $l$ was in the range between $186 \mathrm{~m}$ and $12 \mathrm{~m}$, with $l$ decreasing (the working face was getting closer), $K$ showed a character that increased slightly and then became stable. Particularly, when $l=186 \mathrm{~m}$, 


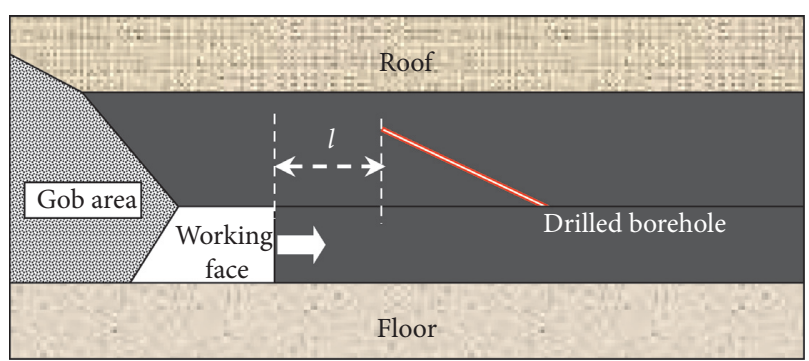

FIgURE 8: Schematic diagram showing the drilled borehole arrangement.

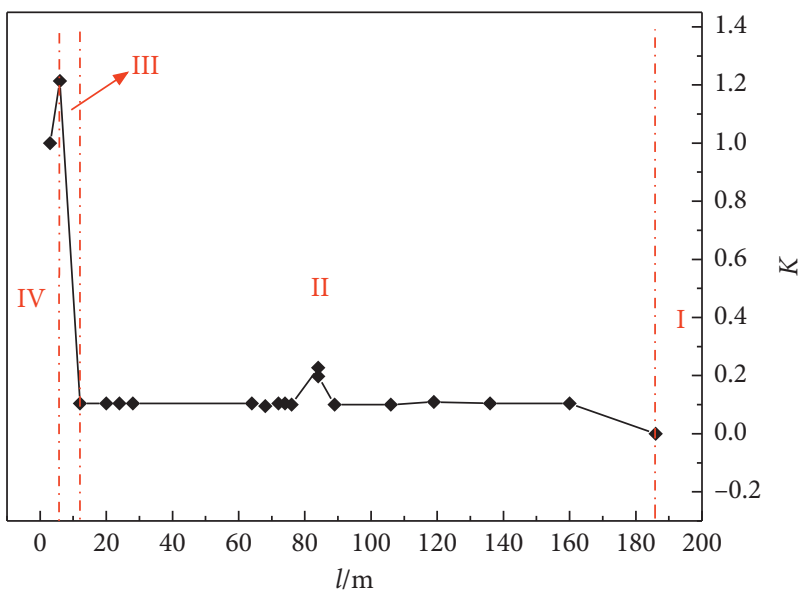

Figure 9: The variation tendency of $K$ with $l$.

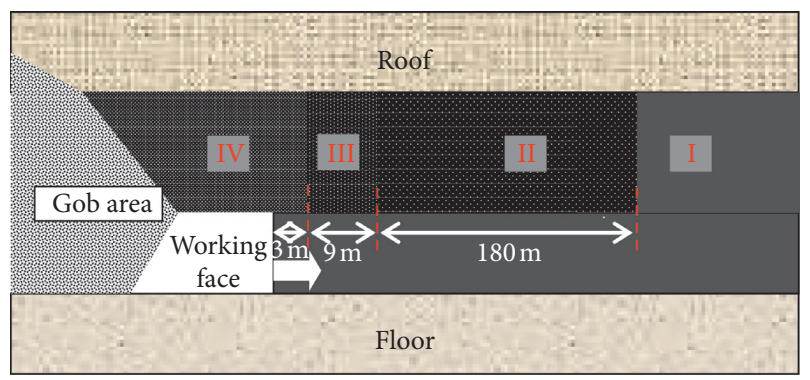

Figure 10: The top coal medium state judgement.

it was 0 . Then, when $l=186 \mathrm{~m}$, it increased to 0.10397 . Then, it stabilised between 0.1 and 0.2 . When $l$ ranged from $12 \mathrm{~m}$ to $6 \mathrm{~m}, K$ increased dramatically to 1.21393 when $l=6 \mathrm{~m}$ and to 0.10397 when $l=12 \mathrm{~m}$. When $l$ ranged from $3 \mathrm{~m}$ to $6 \mathrm{~m}, K$ stabilised around 1 .

According to the medium state index $K$, the medium state judgement model was applied to judge the medium state, as shown in Figure 10. In the coal mass that was $186 \mathrm{~m}$ away from the working face (area I), the influence of the mining disturbing was slight. There was almost no damaging and it was under the intact state. Then, it belonged to the continuous medium state. As for the coal mass that was $6 \mathrm{~m}$ to $186 \mathrm{~m}$ far away from the working face (area II), it was under the quasicontinuous medium state. For the coal mass that was $3 \mathrm{~m}$ to $6 \mathrm{~m}$ far away from the working face (area III), it was under the discontinuous medium state. For the coal mass that was less than $3 \mathrm{~m}$ far away from the working face and behind the working face (area IV), the influence of the mining disturbing was severe. The full damaging failure occurred and the coal mass belonged to the bulk solid medium state. In this area, the bulk solid state of coal masses was beneficial for the caving of the top coal in the fully mechanised caving mining.

\section{Conclusions}

(1) The medium state index $(K)$ was defined. The medium state index was the ratio between the time that the acoustic wave passes through fractures when the rock mass is under a certain failure state and the time that the acoustic wave passes through fractures when the rock mass fully fails.

(2) Aiming at the coal masses in the working face 8512 in the Chenjiagou Coal Mine, the laboratory acoustic character and mechanical character experiments on the loaded rocks were designed. The variation law between the medium state index $(K)$ and the strain was observed. With the strain increasing, $K$ experienced the process including the stabilising around 0 , slight increasing, dramatic increasing, and stabilising around 1.

(3) The medium state judgement model of coal and rock was constructed. When the medium state index of coal and rock masses $(K)$ was in the stabilising stage, which was around 0 , the coal and rock masses were under the continuous medium state. When $K$ was under the gradual increasing stage, the coal and rock masses were under the continuous medium state. Moreover, when $K$ was in the dramatic increasing stage, the coal and rock masses were under the discontinuous state. When $K$ was in the stabilising stage that was around 1 , the coal and rock masses were under the bulk solid medium state. Then, this method was applied to judge the coal mass medium state.

(4) The applicability and rationality of the medium state judgement model was verified. Aiming at the roof mudstones of the same working face, the same experiments and calculating methods were applied, to acquire the variation rule between the mudstone medium state index $(K)$ and strain. According to the medium state judgement model, the mudstone medium state was divided into 4 types: continuous, quasicontinuous, discontinuous, and bulk solid state. The applicability of the medium state judgement model was verified. The failure state of the mudstone samples was basically consistent with the continuous, quasicontinuous, discontinuous, and bulk solid state. Then, the rationality of the medium state judgement model was verified.

(5) The engineering application of the medium state judgement model was conducted. The sound velocity and the medium state index $(K)$ of the top coal that 
was differently far away from the working face were calculated. Then, the distribution rule of the coal masses that were under different medium state was acquired. As for the top coal that was $6 \mathrm{~m}$ to $186 \mathrm{~m}$ far away from the working face, it was under the quasicontinuous medium state. For the top coal that was $3 \mathrm{~m}$ to $6 \mathrm{~m}$ far away from the working face, it was under the discontinuous medium state. For the top coal that was less than $3 \mathrm{~m}$ far away from the working face and behind the working face, it belonged to the bulk solid medium state. The research results were successfully applied in the field.

This article carries out rock acoustic and mechanical characteristics tests by defining media state indicator, proposes a coal rock medium state judgement model, and uses this model to determine the medium state of the coal body and roof mudstone. The applicability of the model is verified. However, it is still necessary to further verify the applicability of the judgement model for other types of rocks.

\section{Data Availability}

The experimental results used to support the findings of this study are included within the article.

\section{Conflicts of Interest}

The authors declare that they have no conflicts of interest regarding the publication of this paper.

\section{Acknowledgments}

The authors are grateful for the financial support received from the Foundation of Educational Commission of Anhui Province (KJ2019A0130) and the National Natural Science Foundation (51904010 and 51574008).

\section{References}

[1] R. Gu and U. Ozbay, "Numerical investigation of unstable rock failure in underground mining condition," Computers and Geotechnics, vol. 63, pp. 171-182, 2015.

[2] M. Rezaei, M. F. Hossaini, and A. Majdi, "A time-independent energy model to determine the height of destressed zone above the mined panel in longwall coal mining," Tunnelling and Underground Space Technology, vol. 47, pp. 81-92, 2015.

[3] B. Regass, N.-X. Xu, and G. Mei, "An equivalent discontinuous modeling method of jointed rock masses for DEM simulation of mining-induced rock movements," International Journal of Rock Mechanics and Mining Sciences, vol. 108, no. 4, pp. 1-14, 2018.

[4] Y. Liu, H. Xiao, K. Yao, J. Hu, and H. Wei, "Rock-soil slope stability analysis by two-phase random media and finite elements," Geoscience Frontiers, vol. 9, no. 6, pp. 1649-1655, 2018.

[5] P. Tommasi, P. Campedel, C. Consorti, and R. Ribacchi, "A discontinuous approach to the numerical modelling of rock avalanches," Rock Mechanics and Rock Engineering, vol. 41, no. 1, pp. 37-58, 2008.

[6] L. O. Afolagboye, J. He, and S. Wang, "Experimental study on cracking behaviour of moulded gypsum containing two non- parallel overlapping flaws under uniaxial compression," Acta Mechanica Sinica, vol. 33, no. 2, pp. 394-405, 2017.

[7] H. Cheng, X. Zhou, J. Zhu, and Q. Qian, “The effects of crack openings on crack initiation, propagation and coalescence behavior in rock-like materials under uniaxial compression," Rock Mechanics and Rock Engineering, vol. 49, no. 9, pp. 3481-3494, 2016.

[8] J. Xu and Z. Li, "Crack propagation and coalescence of steppath failure in rocks," Rock Mechanics and Rock Engineering, vol. 52, no. 4, pp. 965-979, 2019.

[9] M. R. M. Aliha, S. S. Mousavi, A. Bahmani, E. Linul, and L. Marsavina, "Crack initiation angles and propagation paths in polyurethane foams under mixed modes I/II and I/III loading," Theoretical and Applied Fracture Mechanics, vol. 101, pp. 152-161, 2019.

[10] W. Gao, S. Dai, T. Xiao, and T. He, "Failure process of rock slopes with cracks based on the fracture mechanics method," Engineering Geology, vol. 231, pp. 190-199, 2017.

[11] H. Y. Liu, S.-Q. Kou, P. A. Lindqvist, and C.-A. Tang, "Numerical modelling of the heterogeneous rock fracture process using various test techniques," Rock Mechanics and Rock Engineering, vol. 40, no. 2, pp. 107-144, 2007.

[12] T. Saksala, "Modelling of dynamic rock fracture process with a rate-dependent combined continuum damage-embedded discontinuity model incorporating microstructure," Rock Mechanics and Rock Engineering, vol. 49, no. 10, pp. 39473962, 2016

[13] W. Dong, D. Yang, X. Zhou, G. Kastiukas, and B. Zhang, "Experimental and numerical investigations on fracture process zone of rock-concrete interface," Fatigue \& Fracture of Engineering Materials \& Structures, vol. 40, no. 5, pp. 820-835, 2017.

[14] V. Sarfarazi, A. Ghazvinian, W. Schubert, M. Blumel, and H. R. Nejati, "Numerical simulation of the process of fracture of echelon rock joints," Rock Mechanics and Rock Engineering, vol. 47, no. 4, pp. 1355-1371, 2014.

[15] K. He, C. Chen, and B. Li, "Case study of a rockfall in Chongqing, China: movement characteristics of the initial failure process of a tower-shaped rock mass," Bulletin of Engineering Geology and the Environment, vol. 78, no. 5, pp. 3295-3303, 2019.

[16] H.-P. Xie, Fractal-Rock Mechanics, China Science Publishing \& Media Ltd., Beijing, China, 1996.

[17] C. A. Tang, H. Liu, P. K. K. Lee, Y. Tsui, and L. G. Tham, "Numerical studies of the influence of microstructure on rock failure in uniaxial compression - Part I: effect of heterogeneity," International Journal of Rock Mechanics and Mining Sciences, vol. 37, no. 4, pp. 555-569, 2000.

[18] C. A. Tang, L. G. Tham, P. K. K. Lee, Y. Tsui, and H. Liu, "Numerical studies of the influence of microstructure on rock failure in uniaxial compression-part II: constraint, slenderness and size effect," International Journal of Rock Mechanics and Mining Sciences, vol. 37, no. 4, pp. 571-583, 2000.

[19] J. Wang, P. Qiu, J. Ning, L. Zhuang, and S. Yang, "A numerical study of the mining-induced energy redistribution in a coal seam adjacent to an extracted coal panel during longwall face mining: a case study," Energy Science \& Engineering, vol. 8, no. 3, pp. 817-835, 2020.

[20] M. Mosleh, W. Hu, and J. Rostami, "Introduction to rock and soil abrasivity index (RSAI)," Wear, vol. 440, pp. 432-433, 2019.

[21] Q.-F. Chen, T.-C. Yin, and H.-Y. Jia, "Selection of optimal threshold of generalised rock quality designation based on modified blockiness index," Advances in Civil Engineering, vol. 2019, Article ID 1340549, 11 pages, 2019. 
[22] X. Liu, Y. Ding, P. G. Ranjith, and P. Luo, "Hydration index and hydrated constitutive model of clay shale using acoustic frequency spectrum," Energy Science \& Engineering, vol. 7, no. 5, pp. 1748-1766, 2019.

[23] Z. Shan, Z.-W. Yu, X. Li, and Y. Xie, "Damage quantification in concrete under fatigue loading using acoustic emission," Journal of Sensors, vol. 2019, Article ID 1359853, 13 pages, 2019.

[24] Y.-S. Zhang, S.-Y. Zuo, B. Yu, S.-W. Chen, and J.-N. Jia, "Study on bending damage constitutive model and mechanical properties of limestone based on acoustic emission," Advances in Civil Engineering, vol. 2019, Article ID 2031520, 10 pages, 2019.

[25] A. ygała and M. Bukowska, "Identification of temperature effect on post-critical geomechanical properties of loaded sandstones," Arabian Journal of Geosciences, vol. 12, no. 10, pp. 1-10, 2019.

[26] D. Shirole, A. Hedayat, and G. Walton, "Experimental relationship between compressional wave attenuation and surface strains in brittle rock," Journal of Geophysical Research: Solid Earth, vol. 124, no. 6, pp. 5770-5793, 2019.

[27] G.-Z. Sun, Structural Mechanics of Rock Masses, China Science Publishing \& Media Ltd., Beijing, China, 1988.

[28] Y.-H. Wang, K.-Z. Deng, K. Wu, and G.-L. Guo, "On the dynamic mechanics model of mining subsidence," Chinese Journal of Rock Mechanics and Engineering, vol. 22, no. 3, pp. 352-357, 2003.

[29] C.-Q. Zhang, H. Zhou, and X.-T. Feng, "Stability assessment of rockmass engineering based on failure approach index," Rock and Soil Mechanics, vol. 28, no. 5, pp. 888-894, 2018.

[30] S.-H. Li, D. Zhou, J. Wang et al., "Key problem of engineering geomechanics in hydroelectric energy exploitation," Scientia Sinica Physica, Mechanica \& Astronomica, vol. 43, no. 12, pp. 1602-1616, 2013.

[31] J.-A. Wang, X.-G. Han, and P.-Z. Ren, "Identification of the damage state evolution in top coal caving mining," Journal of China Coal Society, vol. 41, no. 1, pp. 1-6, 2016.

[32] C.-Q. Zhu, Study on the mechanical response regularity of media properties of surrounding rock in stope, Ph.D. thesis, AnHui University of Science and Technology, Huainan, China, 2018.

[33] B. Stefan, D. Christie, and A. Chris, "An acoustic sensor for prediction of the structural stability of rock," InternationalJournal of Rock Mechanics and Mining Sciences, vol. 85, no. 3,pp. 187-191, 2016.

[34] J. Hampton, M. Gutierrez, and L. Matzar, "Microcrack damage observations near coalesced fractures using acoustic emission," Rock Mechanics and Rock Engineering, vol. 52, no. 10, pp. 3597-3608, 2019.

[35] F.-J. Yang, D.-W. Hu, H. Zhou, J.-J. Lu, and F. Zhang, "Physical and mechanical properties of granite after dynamic disturbance," Chinese Journal of Rock Mechanics and Engineering, vol. 37, no. 6, pp. 1459-1467, 2018.

[36] Y.-B. Zhang, K.-X. Wang, X. L. Yao et al., "Rock damage evaluation based on wave velocity field imaging technology," Chinese Journal of Rock Mechanics and Engineering, vol. 38, no. 12, pp. 2402-2417, 2019. 